\title{
Neurally adjusted ventilatory assist (NAVA) versus pressure support ventilation: patient-ventilator interaction during invasive ventilation delivered by tracheostomy
}

Olivier Lamouret ${ }^{1,2^{*}}$ (D), Laure Crognier ${ }^{1}$, Fanny Vardon Bounes ${ }^{1}$, Jean-Marie Conil ${ }^{1}$, Caroline Dilasser ${ }^{1}$, Thibaut Raimondi ${ }^{1}$, Stephanie Ruiz ${ }^{1}$, Antoine Rouget ${ }^{1}$, Clément Delmas ${ }^{1}$, Thierry Seguin ${ }^{1}$, Vincent Minville ${ }^{1}$ and Bernard Georges ${ }^{1}$

\begin{abstract}
Background: Prolonged weaning is a major issue in intensive care patients and tracheostomy is one of the last resort options. Optimized patient-ventilator interaction is essential to weaning. The purpose of this study was to compare patient-ventilator synchrony between pressure support ventilation (PSV) and neurally adjusted ventilatory assist (NAVA) in a selected population of tracheostomised patients.
\end{abstract}

Methods: We performed a prospective, sequential, non-randomized and single-centre study. Two recording periods of 60 min of airway pressure, flow, and electrical activity of the diaphragm during PSV and NAVA were recorded in a random assignment and eight periods of 1 min were analysed for each mode. We searched for macro-asynchronies (ineffective, double, and auto-triggering) and micro-asynchronies (inspiratory trigger delay, premature, and late cycling). The number and type of asynchrony events per minute and asynchrony index (Al) were determined. The two respiratory phases were compared using the non-parametric Wilcoxon test after testing the equality of the two variances (F-Test).

Results: Among the 61 patients analysed, the total Al was lower in NAVA than in PSV mode: $2.1 \%$ vs 14\% ( $p<0.0001)$. This was mainly due to a decrease in the micro-asynchronies index: $0.35 \%$ vs $9.8 \%(p<0.0001)$. The occurrence of macroasynchronies was similar in both ventilator modes except for double triggering, which increased in NAVA. The tidal volume $(\mathrm{ml} / \mathrm{kg}$ ) was lower in NAVA than in PSV (5.8 vs 6.2, $p<0.001)$, and the respiratory rate was higher in NAVA than in PSV (28 vs 26, $p<0.05)$.

Conclusion: NAVA appears to be a promising ventilator mode in tracheotomised patients, especially for those requiring prolonged weaning due to the decrease in asynchronies.

Keywords: Neurally adjusted ventilatory assist, Pressure support, Tracheostomy, Difficult weaning, Patient-ventilator asynchronies

\footnotetext{
* Correspondence: olivierlamouret@yahoo.fr

${ }^{1}$ Service de Réanimation Polyvalente, CHU Rangueil, 1 Avenue Jean Poulhès,

Pôle d'Anesthésie et Réanimation, TSA 50032, 31059 Toulouse Cedex 9,

France

${ }^{2}$ Department of Anaesthesiology and Critical Care Unit, University Hospital of

Toulouse, 31059 Toulouse Cedex 9, France
}

C The Author(s). 2019 Open Access This article is distributed under the terms of the Creative Commons Attribution 4.0 International License (http://creativecommons.org/licenses/by/4.0/), which permits unrestricted use, distribution, and reproduction in any medium, provided you give appropriate credit to the original author(s) and the source, provide a link to the Creative Commons license, and indicate if changes were made. The Creative Commons Public Domain Dedication waiver (http://creativecommons.org/publicdomain/zero/1.0/) applies to the data made available in this article, unless otherwise stated. 


\section{Introduction}

Difficult weaning from ventilator support was defined by the consensus conference published in the European Respiratory Journal in 2007 [1]. Nearly half of the patients who fail at the first single-breathing trial still require mechanical ventilation at day $7[2,3]$. Prolonged weaning significantly increases the incidence of ventilator-associated pneumonia (VAP) [4] and mortality [5].

Prolonged weaning could be caused by respiratory or heart failure, intensive care unit (ICU)-acquired weakness $[1,2]$, or be related to poor patient-ventilator interaction (called patient-ventilator asynchrony). According to research, tracheostomy could reduce the duration of mechanical ventilation $[6,7]$ and both $\operatorname{ICU}[6,8]$ and hospital mortality [9].

Patient-ventilator asynchronies occur in approximately $25 \%$ of mechanically ventilated patients, thus increasing the duration of mechanical ventilation and the length of ICU or hospital stays $[10,11]$.

Asynchronies can be divided into macro- and microasynchronies. Macro-asynchronies are generally comprised of ineffective triggering, some double triggering and, more rarely, auto-triggering [10, 12]. Micro-asynchronies comprise inspiratory trigger delay, premature, and late cycling. They may reflect a delay between a diaphragm signal and a respirator response [13]. An inspiratory trigger delay is too big a delay between the diaphragmatic signal and respiratory insufflation. Late cycling, initially called "prolonged cycle" [10], is too long a respiratory insufflation while the patient is already in expiration time (diaphragmatic relaxation) $[14,15]$. These prolonged inspirations favour other asynchronies such as ineffective triggering and are potentially responsible for dynamic hyperinflation that increases both respiratory work and the duration of the ventilator support [16]. We examined a third micro-asynchrony called premature cycling [13], which is defined by a ventilator insufflation stop while the diaphragmatic signal is still in inspiration.

Pressure support ventilation (PSV) is a normal weaning mode. New assisted proportional ventilation modes such as neurally adjusted ventilator assist (NAVA) could help optimise weaning. NAVA mode is based on the detection of a diaphragm electromyographic signal (Eadi) [17] which triggers the ventilator and provides proportional assistance.

The benefits on patient-ventilator synchrony have been well established on intubated patients [13, 18-22].

To our knowledge, no study has compared the occurrence of various asynchronies in NAVA versus PSV on ventilated tracheotomised patients [23].

The objective of our study was to show a reduction of asynchronies in NAVA compared with PSV in mechanically ventilated patients with tracheostomies. The secondary objectives were to compare the different types of asynchronies between NAVA and PSV and other respiratory parameters.

\section{Material and methods}

We conducted a prospective, sequential, non-randomized, single-centre study in the ICU of the University Hospital of Rangueil in Toulouse, France. The study was approved by our institution's Ethics Research Committee (No. 50-0614). The inclusions started in June 2014 for a period of 2 years and 9 months. All ventilated tracheotomised patients were eligible for inclusion. The exclusion criteria were: patients younger than 18 years old, pregnant women, classical contraindications to Eadi catheter placement (recent oesophageal or gastric surgery, presence of oesophageal varices), a progressive infectious process defined by the association with clinical examination or imaging of an infected area with systemic inflammatory response syndrome (SIRS), haemodynamic failure (mean arterial pressure less than $65 \mathrm{mmHg}$ or catecholaminergic treatment), decisions to withhold life-sustaining treatment, and the presence of a guardianship.

\section{Protocol after inclusion}

Included patients benefitted from the placement of an Eadi catheter $16 \mathrm{Fr} / 125 \mathrm{~cm}$ by nasal insertion (Eadi Catheter, Maquet Critical Care ${ }^{\oplus}$, Solna, Sweden).

As described by Sinderby et al. [17], the electrical activity of the diaphragm is obtained through an array of electrodes placed in the oesophagus at the diaphragm level. The signal is amplified and acquired into an online processing unit. The processed signal is amplified and output to a Servo- $\mathrm{i}^{\circ}$ ventilator, which delivers assistance in proportion to the diaphragm's electrical activity.

Positioning of the Eadi catheter was monitored by a special tool implemented in the Servo- $i^{\oplus}$ ventilator.

The correct position of the electrodes in relation to the heart and diaphragm was estimated by assessing the different leads for the presence/absence of the p-wave and QRS complex.

The optimal catheter position was identified through co-existence of three criteria: stable Eadi signal, electrical activity highlighted in the central leads of the catheter's positioning tool, and absence of a p-wave in the distal lead.

Among the included patients, some were ventilated using NAVA prior to tracheostomy (through an orotracheal tube). For the other patients, the Edi catheter was placed just after the tracheostomy procedure. The baseline mode before inclusion could equally be NAVA or PSV.

After inclusion, the tracheotomised patients were mechanically ventilated according to two 60-min recorded periods in a random assignment: PSV followed by NAVA, or NAVA followed by PSV.

An experienced physician adjusted the optimal ventilation settings tailored for each patient in two phases.

We started with a theoretical phase with major targets such as a low tidal volume (VT), a moderate positive 
end-expiratory pressure (PEEP), and an expiratory trigger suited to the respiratory disease. This was followed by a dynamic phase observing the curves as detailed below to improve the settings.

For PSV, the level of support was the minimum level to obtain a VT expired (VTe) between 6 and $8 \mathrm{ml} / \mathrm{kg}$ of predicted body weight (PBW).

Inspiratory trigger in-flow was adjusted as low as possible without auto-triggering. The expiratory trigger was set between $20 \%$ and $50 \%$, depending on the past medical history of a restrictive (low trigger), obstructive syndrome (high trigger), or none (intermediate trigger of $25 \%$ to $30 \%)$.

A moderate PEEP level seems to be an appropriate compromise during the weaning process.

External PEEP and expiratory cycling were simultaneously optimised through the flow curves of the ventilator, such as the expiratory flow returning to zero which reflects the absence of major auto-PEEP.

The PEEP level was determined for PSV and we used the same level for NAVA.

In NAVA, the "preview NAVA" function of the Servo- $i^{\circ}$ ventilator was used to estimate the NAVA gain to obtain the same peak pressure as that during PSV, and VT between 6 and $8 \mathrm{ml} / \mathrm{kg}$ of PBW. If $\mathrm{VTe}$ exceeded $8 \mathrm{ml} / \mathrm{kg}$, we decreased the NAVA level.

The Eadi inspiratory trigger was set to a predetermined default value of $0.5 \mu \mathrm{V}$, always above the minimal value of the patient's Eadi. The cycle-off value was set to $80 \%$ of the Eadi peak in the NAVA mode. In NAVA, the first inspiratory trigger detected (pneumatic or neurally) is rewarded by a respirator insufflation.

The Eadi catheter was susceptible to movement. NAVA includes a safety feature. If the Eadi signal exhibits artefacts or is lost, the ventilator automatically reverts to PSV.

We checked the correct position of the Eadi catheter at the start and at the end of the recording. We looked for a stable nose tip measurement and we used the special tool implemented in the Servo-i ventilator to verify the optimal position based on the co-existence of the three criteria, as previously mentioned.

All the settings were kept constant and the same patient body position was used during the entire recording process and for the two modes.

\section{Data collection}

Data were recorded using Servo-i software CPR (Maquet Critical Care ${ }^{\oplus}$, Solna, Sweden). Pressure, flow, volume curves, diaphragmatic signals (Eadi), VT, and assistance levels were collected for each patient. If a patient required aspiration, the nurse disconnected the circuit during the recording process which was easy to detect on the records (loss of flow and pressure curve).

\section{Data analysis}

Two independent physicians analysed the recorded data. In the event of a mismatch, a third physician was used. Analysis of the respiratory curves was performed manually by examining eight recording periods of $1 \mathrm{~min}$ at regular intervals of $8 \mathrm{~min}$ for each mode, which represented an analysis period of $16 \mathrm{~min}$ for each patient.

If one of these 1-min periods showed an artefact (the patient disconnected for any reason, secretions in the ventilator circuit, cough), we analysed the following minute.

Six types of asynchrony were analysed (Fig. 1). Macroasynchronies have been previously described by Thille et al. [10]: ineffective triggering (Fig. 1a) was defined by the existence of a diaphragmatic signal without a respiratory cycle; auto-triggering (Fig. 1b) was defined by the existence of a ventilator cycle without a diaphragmatic signal; double triggering (Fig. 1c) was defined by the presence of two successive inspiratory cycles without an intermediate expiration or with an interrupted expiration.

Micro-asynchronies were defined by a delay exceeding 200 ms: between diaphragmatic contractions and the start of insufflation-inspiratory trigger (Fig. 1e); between the end of diaphragmatic contractions and the opening of the expiratory valve-late cycling (Fig. 1f); and between the end of diaphragmatic contractions and the opening of the expiratory valve-premature cycling (Fig. 1d).

In the absence of a consensual definition, we used a delay of $150 \mathrm{~ms}$ for each type of micro-asynchrony, which represents the conscious perception threshold which could be a source of discomfort [24]. We added a 50-ms safety margin.

The total number of asynchronies was then calculated for each ventilation mode by adding different asynchronies recorded during eight periods of $1 \mathrm{~min}$ for a total of $1 \mathrm{~h}$ of recording.

An asynchrony index (AI) was calculated. This index corresponds to the total number of asynchrony events divided by the total respiratory rate (which corresponds to the total Eadi signals) $\times 100[10,13]$. The AI was expressed as a percentage.

For each subtype of asynchrony, a percentage of asynchronies was calculated as follows: number of asynchrony events divided by the total Eadi signals $\times 100$. In addition, we calculated the VT in $\mathrm{ml} / \mathrm{kg}$ of PBW, corresponding to the different recording periods. The variability of VT in each ventilation mode was evaluated by the coefficient of variation.

\section{Statistical analysis}

The characteristics of the population and of the analysed variables are described as medians and 95\% confidence intervals. The two respiratory phases were compared 


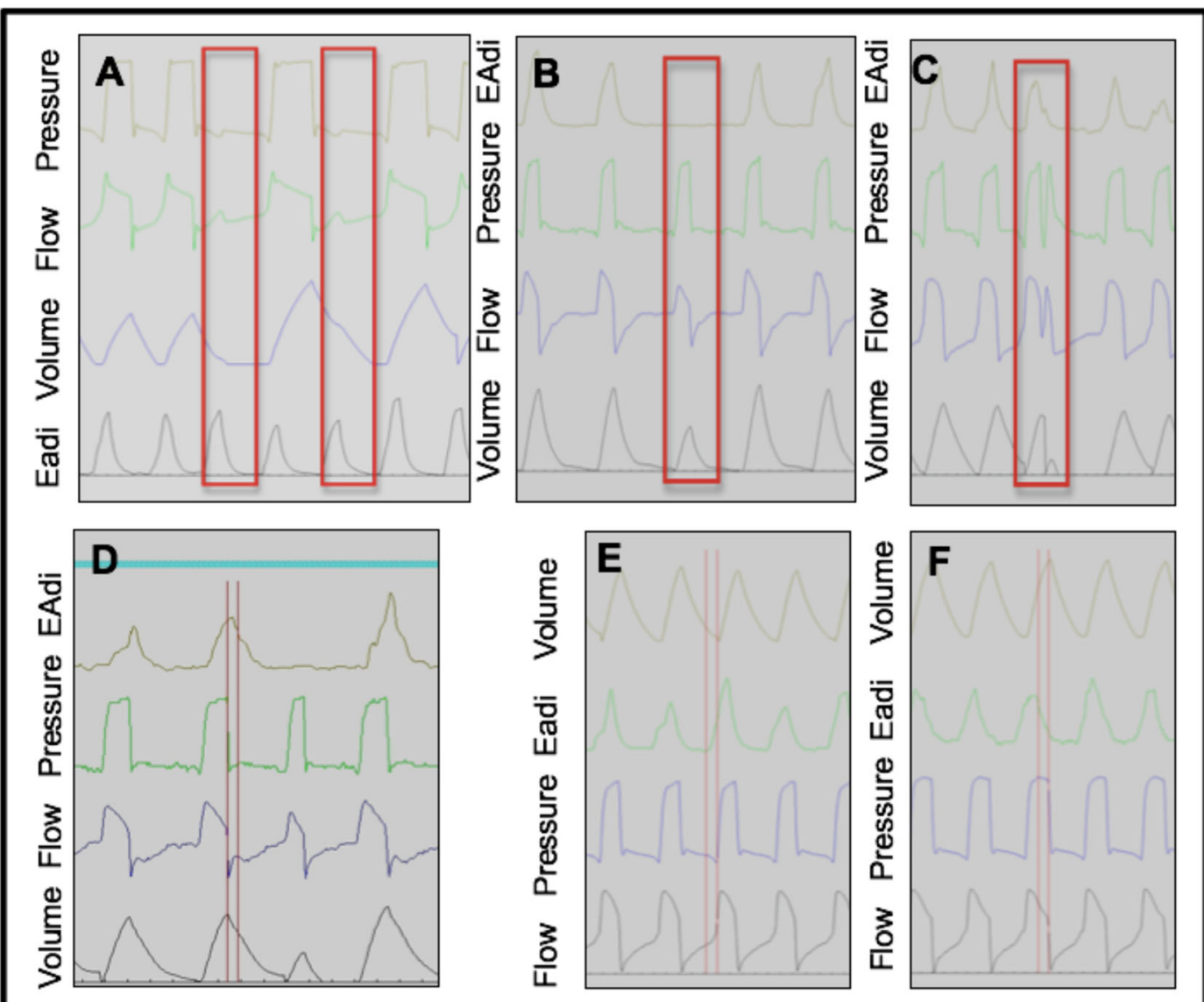

Fig. 1 Description of asynchronies studied. a Ineffective triggering; b auto-triggering; c double triggering; $\mathbf{d}$ premature cycling; e inspiratory trigger delay; $\mathbf{f}$ late cycling. EAdi electrical activity of the diaphragm

using the non-parametric Wilcoxon test after testing the equality of the two variances (F-Test).

The objective was to demonstrate a decrease in the total number of patient-ventilator asynchronies and in AI. Power analysis indicated that a sample size of 28 was sufficient to demonstrate a $20 \%$ reduction in the number of asynchronies between the PSV and NAVA modes, with $\alpha$ and $\beta$ risks of 0.05 and 0.20 , respectively.

The analysis was performed with MedCalc ${ }^{\circ} 15$ statistical software (Ostend, Belgium). The difference between the groups was considered statistically significant for $p$ values $<0.05$.

\section{Results}

\section{Population}

A total of 66 out of 130 eligible patients (50.8\%) were included (Fig. 2). Three recordings were uninterpretable due to a heavy number of artefacts and two measurements were not recorded. Finally, a total of 61 patients were analysed (46.9\%).

The main characteristics of the population are presented in Table 1, where the results are expressed as the median and range and a 95\% confidence interval or as a number and percentage.

The population presented with a median Simplified Acute Physiology Score (SAPS) II of 59 (range 22-93). The majority of patients were male (72.1\%), with a median age of 65 years (range 32-85). Over one-third of the patients had a known respiratory disease, mainly chronic obstructive pulmonary disease (COPD), and nearly half of the patients had past cardiac medical history. Nearly $46 \%$ failed extubation after a positive spontaneous breathing trial (SBT).

The median length of time between ICU admission and tracheostomy was 21 (95\% confidence interval 19-26) days with a median time of mechanical ventilation of 39 (95\% confidence interval 33-44) days.

All-cause mortality was high; $45.9 \%$ of patients $(n=28)$ died during their hospital stay.

\section{Ventilator settings and asynchronies}

Ventilator settings are shown in Table 2. The median level of support was 10 (range 3-24) $\mathrm{cmH}_{2} \mathrm{O}$ in PSV and 0.6 (range $0.1-3$ ) $\mathrm{cmH}_{2} \mathrm{O} / \mu \mathrm{V}$ in NAVA. The inspiratory flow trigger level was set at a median of 6 (range 1-9) 


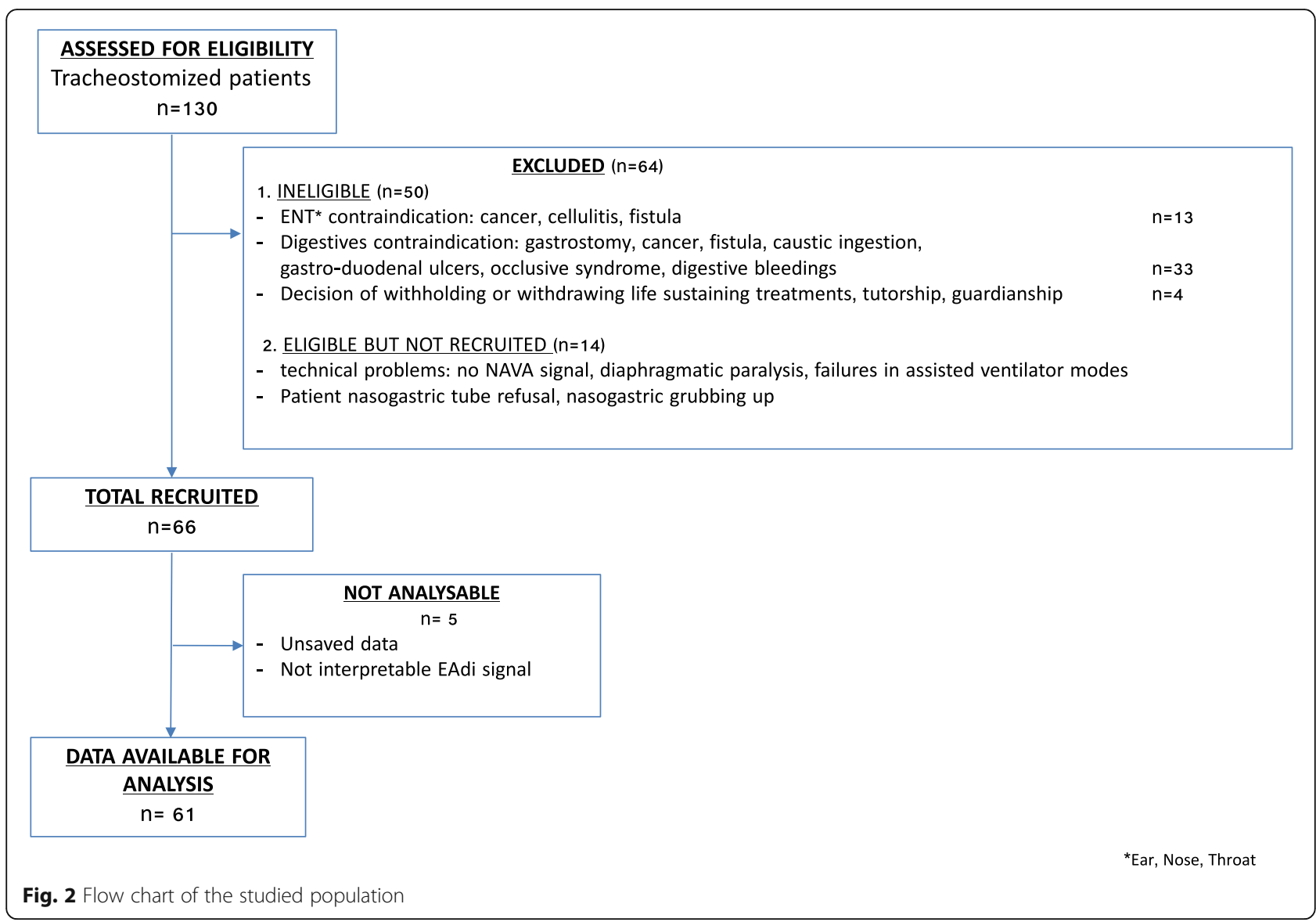

(the Maquet trigger range from 1 to 10 corresponds to 3 to $1 \mathrm{l} / \mathrm{min}$ ). The expiratory trigger was set according to the patient's respiratory restrictive or obstructive status or by considering a dynamic lung hyperinflation. The median expiratory trigger was set at 30\% (range 15-50). PEEP was significantly lower in NAVA than PSV (5 versus $6 \mathrm{cmH}_{2} \mathrm{O}$ ).

The total asynchrony index was lower in NAVA than in PSV (2.1\% vs $14 \%, p<0.0001)$ (Fig. 3). Similarly, an AI > $10 \%$ was less frequent in NAVA than in PSV mode $(11.5 \%$ vs $62.3 \%, p<0.0001)$. Among the macro-asynchronies, there was no difference in auto-triggering and ineffective triggering between the two groups. However, there was more double triggering in NAVA than in PSV $(0.4 \%$ vs $0.3 \%, p<0.01)$.

Regarding micro-asynchronies, there were less of each type in NAVA mode than in PSV mode.

The tidal volume was lower in NAVA than in PSV (5.8 vs $6.2 \mathrm{ml} / \mathrm{kg}, p<0.001)$. The respiratory rate was higher in NAVA than in PSV (28 vs 26 breaths/min, $p<0.05$ ).

\section{Discussion}

Difficult weaning from ventilator support requires optimal ventilation settings. Here, we demonstrated in a prospective study that NAVA reduced total patient-ventilator asynchronies mainly through a decrease of micro-asynchronies in tracheotomised patients in comparison with the PSV mode.

Generally, tracheostomy is performed in the ICU for difficult weaning and prolonged ventilation or to protect the upper airways in brain-injured patients. In our population, a majority of the patients were tracheotomised for difficult weaning.

Frutos-Vivar et al. [8] showed in a large multicentric observational study that tracheostomy is mainly performed in the context of respiratory diseases. A minority of $22 \%$ of the patients included were tracheotomised due to a coma.

In comparison to this previous study, there were several comas (less than 10\%), except for post-anoxic coma, because of the coexistence of a neurosurgical ICU in the same University Hospital.

Another specific feature of our study was the important role of patients with cardiac and respiratory diseases, these representing a particular population for whom weaning would be difficult.

We did not precisely quantify the ICU-acquired weakness but, as recently established, weaning failure is not associated with a poor Medical Research Council (MRC) score [25]. 
Table 1 Main characteristics of the population

\begin{tabular}{|c|c|c|c|c|}
\hline Total population $(n=61)$ & Median & $95 \% \mathrm{Cl}$ & Minimum & Maximum \\
\hline Age (years) & 65 & $63-66.6$ & 32 & 85 \\
\hline BMI $\left(\mathrm{kg} / \mathrm{m}^{2}\right)$ & 27.7 & $25.4-29.5$ & 20.4 & 39 \\
\hline SAPS ॥ & 59 & $53-69$ & 22 & 93 \\
\hline Men/women, $n(\%)$ & \multicolumn{2}{|c|}{$44(72.1 \%) / 17(27.9 \%)$} & & \\
\hline Duration of MV (days) & 39 & $33-44$ & 15 & 164 \\
\hline Weaning period (days) & 21 & $19-26$ & 2 & 58 \\
\hline Extubation failure $(n)$ & 0 & $0-1$ & 0 & 4 \\
\hline ICU stay (days) & 43 & $36.4-53$ & 13 & 169 \\
\hline \multicolumn{5}{|l|}{ Respiratory disease, $n$ (\%) } \\
\hline COPD & $18(29.5 \%)$ & & & \\
\hline Restrictive syndrome & $6(9.8 \%)$ & & & \\
\hline \multicolumn{5}{|l|}{ Cardiac disease, $n(\%)$} \\
\hline Coronary disease & 19 (31.1\%) & & & \\
\hline Heart failure & $10(16.4 \%)$ & & & \\
\hline \multicolumn{5}{|l|}{ Obesity, n (\%) } \\
\hline Normal weight & $21(34.4 \%)$ & & & \\
\hline Overweight & 19 (31.1\%) & & & \\
\hline Moderate obesity (BMI $30-35 \mathrm{~kg} / \mathrm{m}^{2}$ ) & $16(26.2 \%)$ & & & \\
\hline Severe obesity (BMI > 35 kg/m²) & $5(8.2 \%)$ & & & \\
\hline \multicolumn{5}{|l|}{ Postoperative, $n(\%)$} \\
\hline Digestive surgery & $2(3.3 \%)$ & & & \\
\hline Cardiothoracic and vascular surgery & $22(36.1 \%)$ & & & \\
\hline Day 28 mortality, $n$ (\%) & $3(4.9 \%)$ & & & \\
\hline Day 90 mortality, $n(\%)$ & $28(45.9 \%)$ & & & \\
\hline
\end{tabular}

$B M I$ body mass index, $C l$ confidence interval, COPD chronic obstructive pulmonary disease, ICU intensive care unit, $M V$ mechanical ventilation, SAPS /I Simplified Acute Physiology Score II

Unfortunately, not all the tracheotomised patients were included (almost 50\%), with the majority of them presenting contraindications to the nasogastric tube.

We also lost some potentially eligible patients because of the small number of Servo- $i^{\oplus}$ devices in our unit. When a patient benefited from NAVA using another interface (orotracheal tube, non-invasive ventilation (NIV)), it would have been unethical to exchange the machine for the gain of a potentially included patient. When several patients were tracheotomised and several Servo- $\mathrm{i}^{\ominus}$ ventilators were available, we favoured patients with the most difficult weaning. In addition, we had to deal with catheter shortages for a few weeks.

Our results exhibited some macro-asynchronies in PSV mode, compared with the $10 \%$ reported in the literature $[10,26]$. This benefit can be attributed to the combined effects of tracheostomy and a careful personalized ventilator setting.

Thille et al. showed that optimized PSV settings help avoid patient-ventilator asynchronies and are related to a reduced weaning period, even in tracheotomised patients
[10]. The same team also demonstrated that reducing pressure support or inspiratory duration eliminated ineffective triggering in a majority of the patients with a high percentage of ineffective efforts [16]. Consequently, we showed no difference in AI between the PSV and NAVA in macroasynchronies (1.6\% in PSV versus $1.64 \%$ in NAVA) despite the proportional assistance applied by NAVA which is known to reduce asynchronies $[13,17,18,20,21,27,28]$.

As previously published by our team [21] and by Piquilloud et al. [13], there was more double triggering in NAVA compared with PSV. The existence of a biphasic aspect of the Eadi signal could explain a successive respiratory cycle during diaphragmatic relaxation (type 1 double triggering) [13], but the occurrence of double triggering was very rare in both modes $(0.3 \%$ in PSV and $0.4 \%$ in NAVA).

Contrary to research on NIV [27] and intubated mechanically ventilated (IMV) patients [10, 13, 18, 29], we did not identify a decrease in the rate of ineffective triggering in NAVA versus PSV. But, as previously noticed, theses asynchronies were rare in our work. 
Table 2 Ventilation settings and asynchronies recorded

\begin{tabular}{|c|c|c|c|c|c|c|c|c|c|}
\hline \multirow[t]{2}{*}{ Total population $(n=61)$} & \multicolumn{4}{|l|}{ PSV } & \multicolumn{4}{|l|}{ NAVA } & \multirow[t]{2}{*}{$p$} \\
\hline & Median & $95 \% \mathrm{Cl}$ & Minimum & Maximum & Median & $95 \% \mathrm{Cl}$ & Minimum & Maximum & \\
\hline Level of support & $10^{\mathrm{a}}$ & $8-12$ & 3 & 24 & $0.6^{\mathrm{b}}$ & $0.5-0.8$ & 0.1 & 3 & NA \\
\hline Expiratory trigger PSV (\%) & 30 & $30-35$ & 15 & 50 & NA & NA & NA & NA & NA \\
\hline Inspiratory trigger PSV (1-10) & 6 & $5-6$ & 1 & 9 & NA & NA & NA & NA & NA \\
\hline \multicolumn{10}{|l|}{ Macro-asynchronies } \\
\hline Auto-triggering & 0 & $0-0.2$ & 0 & 4.1 & 0 & $0-0.08$ & 0 & 24 & 0.0182 \\
\hline$\%$ auto-triggering & 0 & $0-0.6$ & 0 & 18.4 & 0 & $0-0.19$ & 0 & 24 & 0.0251 \\
\hline Double triggering & 0.1 & $0-0.3$ & 0 & 5.3 & 0.1 & $0-0.20$ & 0 & 24 & 0.0223 \\
\hline$\%$ double triggering & 0.3 & $0-0.5$ & 0 & 16.6 & 0.4 & $0-0.79$ & 0 & 24 & 0.0063 \\
\hline Ineffective triggering & 0 & $0-0.08$ & 0 & 14.4 & 0 & $0-0.13$ & 0 & 24 & 0.4363 \\
\hline$\%$ ineffective triggering & 0 & $0-0.19$ & 0 & 33.9 & 0 & $0-0.46$ & 0 & 24 & 0.3272 \\
\hline Macro-asynchrony index (\%) & 1.6 & $1-3.18$ & 0 & 33.9 & 1.64 & $0.4-2.5$ & 0 & 24 & 0.6420 \\
\hline \multicolumn{10}{|l|}{ Micro-asynchronies } \\
\hline Premature cycling-off & 0.13 & $0-0.6$ & 0 & 4 & 0 & $0-0$ & 0 & 24 & $<0.0001$ \\
\hline$\%$ premature cycling-off & 0.3 & $0-1.9$ & 0 & 31 & 0 & $0-0$ & 0 & 24 & $<0.0001$ \\
\hline Late cycling-off & 0.123 & $0-0.38$ & 0 & 11.4 & 0 & $0-0$ & 0 & 24 & 0.0002 \\
\hline$\%$ late cycling-off & 0.5 & $0-1.24$ & 0 & 27.7 & 0 & $0-0$ & 0 & 66 & 0.0013 \\
\hline Inspiratory trigger delay & 0.88 & $0.5-1.75$ & 0 & 25.9 & 0 & $0-0.13$ & 0 & 24 & $<0.0001$ \\
\hline$\%$ inspiratory trigger delay & 3.55 & $1.8-5.96$ & 0 & 81.9 & 0 & $0-0.4$ & 0 & 24 & $<0.0001$ \\
\hline Micro-asynchrony index (\%) & 9.8 & $6.8-15.7$ & 0 & 100.7 & 0.35 & $0-0.86$ & 0 & 24 & $<0.0001$ \\
\hline \multicolumn{10}{|l|}{ Total asynchronies } \\
\hline Total Al (\%) & 14 & $9.9-21.7$ & 0 & 101.8 & 2.1 & $0.8-3.9$ & 0 & 24 & $<0.0001$ \\
\hline Patients with Al > 10\% & & 38 & $62.3 \%$ & & & 7 & $11.5 \%$ & & \\
\hline Respiratory rate (cycle/min) & 28 & $25-29$ & 12.6 & 46 & 26 & $25-28$ & 11 & 46.6 & 0.0323 \\
\hline VT expired (ml) & 400 & $381-418$ & 194.8 & 947 & 366 & $336-388$ & 207.1 & 982 & 0.0020 \\
\hline Volume/min (I/min) & 11.4 & $10-13$ & 5.5 & 21.7 & 11.4 & $11-12.2$ & 6 & 20.4 & 0.8953 \\
\hline VT (ml/kg PBW) & 6.2 & $5.9-6.4$ & 3.1 & 12.4 & 5.8 & $5.3-6.2$ & 3.3 & 12.9 & 0.0009 \\
\hline PEEP $\left(\mathrm{cmH}_{2} \mathrm{O}\right)$ & 6 & $5-6$ & 3 & 10 & 5 & $5-5$ & 3 & 10 & 0.0029 \\
\hline Eadi peak & 15.7 & $12.4-19.7$ & 3.3 & 84.75 & 15.2 & $12.5-18.2$ & 6.72 & 84 & 0.1142 \\
\hline
\end{tabular}

Results are expressed as medians, $95 \%$ confidence intervals (Cls) or number (\%) Significant $p$ values are shown in bold typeface

Al asynchrony index, Eadi electrical activity of the diaphragm, NA not available, NAVA neurally adjusted ventilatory assist, PDW predicted body weight, PEEP positive end-expiratory pressure, $P S V$ pressure support ventilation, $V T$ tidal volume

${ }^{\text {a }}$ Results expressed in $\mathrm{cmH}_{2} \mathrm{O}$

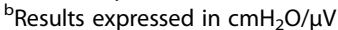

To our knowledge, one study [23] compared patientventilator interactions in NAVA versus PSV on tracheotomised patients during the weaning process. The authors assessed the physiological response to varying levels of NAVA and PSV in 13 tracheotomised patients. Patientventilator asynchrony was not fully investigated. They only explored ineffective triggering rates, which were not significantly different between the two modes, independently from the level of assistance. This could be explained by the specific interface (tracheostomy) which allows for a decrease in dead space and airway resistance in both ventilator modes. Consequently, it could limit dynamic lung hyperinflation and auto-PEEP.
Our study shows a significant decrease in the total asynchrony index in NAVA versus PSV $(2.1 \%$ vs $14 \%$, $p<0.0001)$. Thille et al. showed that patients whose asynchrony index was greater than $10 \%$ had a longer duration of mechanical ventilation [10] and higher mortality [28]. But the difference on AI only focuses on micro-asynchronies. The micro-asynchrony index was statistically significant lower in NAVA than in PSV (0.35\% versus $9.8 \%)$.

Despite particular attention being paid to ventilator settings to limit dynamic lung hyperinflation in PSV (personalization of inspiratory trigger, low pressure support level), there was less late cycling in NAVA. In NAVA, the 


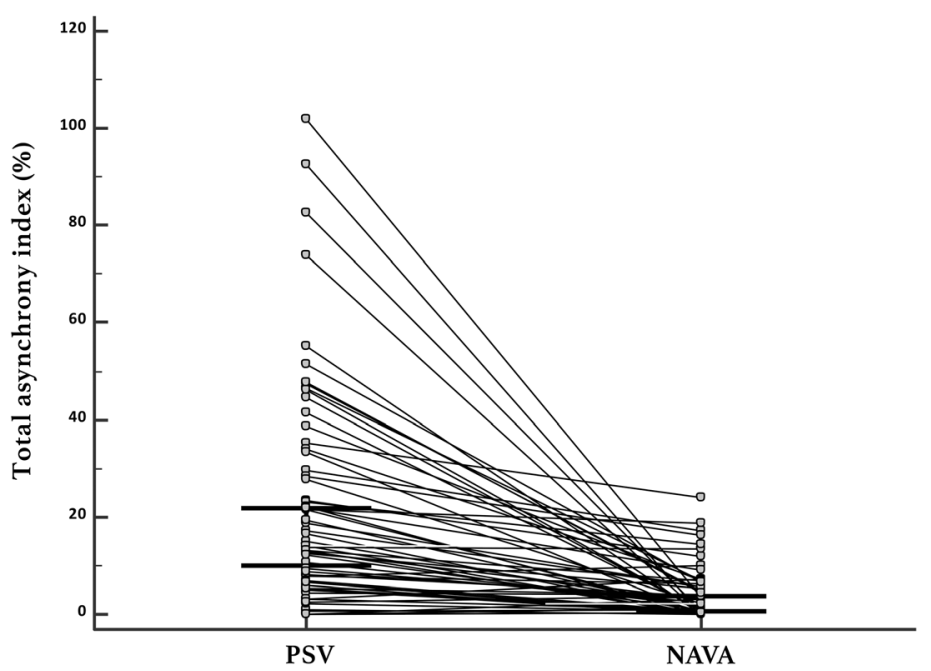

Fig. 3 Primary objective; total asynchrony index in neurally adjusted ventilatory assist (NAVA) versus pressure support ventilation (PSV)

level of assistance is proportional to the patient request and the expiratory trigger is neural, preset to $80 \%$ of the Eadi peak. These specificities allow for an optimization of the respiratory parameters from one cycle to the next, with a continuous variability of the pressure support level $\left(\mathrm{cmH}_{2} \mathrm{O} / \mu \mathrm{V}\right)$ and the expiratory timing. This result strengthens previous studies that underline the importance of a personal and adapted cycling-off to avoid dynamic hyperinflation, especially in COPD patients [14, 29].

There was little premature cycling in NAVA. This makes sense because, in NAVA, expiratory triggers are systematically neural.

We defined an asynchrony as a delay of 150 ms between the origin of the Eadi signal and the start of the ventilator insufflation, which represents the conscious perception threshold that could be source of discomfort. Consequently, we added a 50-ms safety margin. In other studies, inspiratory delays were measured and the durations were compared based on the ventilator mode [13, 18, 20, 27, 30].

The median respiratory rate ( 26 versus 28 breaths/min) and the median tidal volume were lower in NAVA than in PSV $(5.8 \mathrm{ml} / \mathrm{kg}$ versus $6.2 \mathrm{ml} / \mathrm{kg})(p<0.001)$. Furthermore, the Eadi peak was similar in both modes. It has been shown that over-assistance is reflected by a decrease in the Eadi peak [19, 23, 30]. This eliminates the possibility of a disparity in the level of assistance between the two modes. PEEP was lower in NAVA (5 versus $6 \mathrm{cmH}_{2} \mathrm{O}$ ). Better expiratory cycling may limit overdistension and allow for a decrease in PEEP.

Our study has some limitations. This was a single-centre observational study, and was non-randomized. This study demonstrated a reduction in asynchronies in NAVA versus PSV but these results could not lead to an assumption of a benefit concerning weaning duration, hospital length of stay, or survival, mainly due to the small population studied.
Prospective clinical studies comparing the weaning from ventilator support in tracheotomised patients with NAVA versus PSV are necessary.

\section{Conclusion}

This is the first study to compare patient-ventilator asynchronies in NAVA and PSV in tracheotomised patients presenting with difficult weaning criteria. There were fewer asynchronies in NAVA with reduced auto-triggering, premature cycling-off, late cycling-off, and inspiratory trigger delay compared with PSV. An asynchrony index greater than $10 \%$, which is related to an increased duration of ventilation, was lower in NAVA. Further studies are required to determine the clinical impact of NAVA on major outcomes in tracheotomised patients.

\section{Abbreviations \\ Al: Asynchrony index; COPD: Chronic obstructive pulmonary disease; Eadi: Electrical activity of the diaphragm; ICU: Intensive care unit; NAVA: Neurally adjusted ventilatory assist; PDW: Predicted body weight; PEEP: Positive end-expiratory pressure; PSV: Pressure support ventilation; SAPS: Simplified Acute Physiology Score; VAP: Ventilator-associated pneumonia; VT: Tidal volume}

\section{Acknowledgements}

We would like to thank the medical and paramedical teams from Rangueil Critical Care Unit.

\section{Funding}

None.

Availability of data and materials

All the data are recorded in our institution. Original data are available from the corresponding author on reasonable request.

\section{Authors' contributions}

Conception and design: $\mathrm{BG}, \mathrm{LC}, \mathrm{OL}, \mathrm{JMC}$, and VM. Analysis and interpretation: $L C, J M C, B G, O L, T R, C D$ and VM. Drafting the manuscript for important intellectual content: BG, OL, AR, CD, SR, TS, and FVB. All authors read and approved the final manuscript. 


\section{Ethics approval and consent to participate}

The study was approved by the Ethics Research Committee of our institution (No. 50-0614).

\section{Consent for publication}

Not applicable.

\section{Competing interests}

The authors declare that they have no competing interests.

\section{Publisher's Note}

Springer Nature remains neutral with regard to jurisdictional claims in published maps and institutional affiliations.

\section{Received: 29 August 2018 Accepted: 4 December 2018}

Published online: 07 January 2019

\section{References}

1. Boles J-M, Bion J, Connors A, Herridge M, Marsh B, Melot C, et al. Weaning from mechanical ventilation. Eur Respir J. 2007;29:1033-56.

2. Esteban A, Alía I, Ibañez J, Benito S, Tobin MJ. Modes of mechanical ventilation and weaning. A national survey of Spanish hospitals. Spanish Lung Failure Collaborative Group. Chest. 1994;106:1188-93.

3. Brochard L, Krauss A, Benito S, et al. Comparison of three methods of gradual withdrawal from ventilatory support during weaning from mechanical ventilation. Am J Respir Crit Care Med. 1994;150:896-903.

4. Langer M, Mosconi P, Cigada M, Mandelli M. Long-term respiratory support and risk of pneumonia in critically ill patients. Intensive Care Unit Group of Infection Control. Am Rev Respir Dis. 1989;140(2):302-5.

5. Chastre J, Fagon JY, et al. State of the Art. Ventilator-associated pneumonia. Am J Respir Crit Care Med. 2002;165(7):867-903.

6. Rumbak MJ, Newton M, Truncale T, Schwartz SW, Adams JW, Hazard PB. A prospective, randomized, study comparing early percutaneous dilational tracheotomy to prolonged translaryngeal intubation (delayed tracheotomy) in critically ill medical patients. Crit Care Med. 2004;32(8):1689-94.

7. Hosokawa K, Nishimura M, Egi M, Vincent J-L. Timing of tracheotomy in ICU patients: a systematic review of randomized controlled trials. Crit Care. 2015; 19:424.

8. Frutos-Vivar F, Esteban A, Apezteguia C, et al. Outcome of mechanically ventilated patients who require a tracheostomy. Crit Care Med. 2005;33:290.

9. Combes A, Luyt CE, Nieszkowska A, Trouillet JL, Gibert C, Chastre J. Is tracheostomy associated with better outcomes for patients requiring longterm mechanical ventilation? Crit Care Med. 2007;35(3):802-7.

10. Thille AW, Rodriguez P, Cabello B, Lellouche F, Brochard L. Patient-ventilator asynchrony during assisted mechanical ventilation. Intensive Care Med. 2006:32:1515-22.

11. de Wit M, Miller KB, Green DA, Ostman HE, Gennings C, Epstein SK. Ineffective triggering predicts increased duration of mechanical ventilation. Crit Care Med. 2009;37:2740-5.

12. Branson RD, Blakeman TC, Robinson BRH. Asynchrony and dyspnea. Respir Care juin. 2013;58:973-89.

13. Piquilloud L, Vignaux L, Bialais E, Roeseler J, Sottiaux T, Laterre P-F, et al. Neurally adjusted ventilatory assist improves patient-ventilator interaction. Intensive Care Med. 2011;37:263-71.

14. Parthasarathy S, Jubran A, Tobin MJ. Cycling of inspiratory and expiratory muscle groups with the ventilator in airflow limitation. Am J Respir Crit Care Med. 1998;158:1471-8.

15. Beck J, Gottfried SB, Navalesi P, Skrobik Y, Comtois N, Rossini M, et al. Electrical activity of the diaphragm during pressure support ventilation in acute respiratory failure. Am J Respir Crit Care Med. 2001;164:419-24.

16. Thille AW, Cabello B, Galia F, Lyazidi A, Brochard L. Reduction of patientventilator asynchrony by reducing tidal volume during pressure-support ventilation. Intensive Care Med. 2008;34:1477-86.

17. Sinderby C, Navalesi P, Beck J, Skrobik Y, Comtois N, Friberg S, Gottfried SB, Lindstrom $L$. Neural control of mechanical ventilation in respiratory failure. Nat Med. 1999;5:1433-6.

18. Spahija J, de Marchie M, Albert M, Bellemare P, Delisle S, Beck J, et al. Patient-ventilator interaction during pressure support ventilation and neurally adjusted ventilatory assist. Crit Care Med. 2010;38(2):518-26.

19. Terzi N, Pelieu I, Guittet L, Ramakers M, Seguin A, Daubin C, et al. Neurally adjusted ventilatory assist in patients recovering spontaneous breathing after acute respiratory distress syndrome: physiological evaluation. Crit Care Med. 2010;38(9):1830-7.

20. Mauri T, Bellani G, Grasselli G, Confalonieri A, Rona R, Patroniti N, et al. Patient-ventilator interaction in ARDS patients with extremely low compliance undergoing ECMO: a novel approach based on diaphragm electrical activity. Intensive Care Med. 2013;39(2):282-91.

21. Yonis H, Crognier L, Conil J-M, Serres I, Rouget A, Virtos M, et al. Patientventilator synchrony in neurally adjusted ventilatory assist (NAVA) and pressure support ventilation (PSV): a prospective observational study. BMC Anesthesiol. 2015;15:117.

22. Kuo NY, Tu ML, Hung TY, Liu SF, Chung YH, Lin MC, Wu CC. A randomized clinical trial of neurally adjusted ventilatory assist versus conventional weaning mode in patients with COPD and prolonged mechanical ventilation. Int J Chron Obstruct Pulmon Dis. 2016;11:945-51.

23. Vagheggini SM, Panai EV, Navalesi P, Ambrosino N. Physiologic response to various levels of pressure support and NAVA in prolonged weaning. Respir Med. 2013;107:1748-54.

24. Whitelaw WA, Derenne JP, Milic-Emili J. Occlusion pressure as a measure of respiratory center output in conscious man. Respir Physiol. 1975;23(2):181-99.

25. Dres M, Dube BP, Mayaux J, Delemazure J, Reuter D, Brochard L, Similowski T, Demoule A. Coexistence and impact of limb muscle and diaphragm weakness at time of liberation from mechanical ventilation in medical intensive care unit patients. Am J Respir Crit Care Med. 2017;195:57-66.

26. Chao DC, Scheinhorn DJ, Stearn-Hassenpflug M. Patient-ventilator trigger asynchrony in prolonged mechanical ventilation. Chest. 1997;112:1592-9.

27. Piquilloud L, Tassaux D, Bialais $\mathrm{E}$, et al. Neurally adjusted ventilatory assist (NAVA) improves patient-ventilator interaction during non-invasive ventilation delivered by face mask. Intensive Care Med. 2012;38:1624-31.

28. Blanch L, Villagra A, Sales B, Montanya J, Lucangelo U, Lujan M, GarciaEsquirol O, Chacon E, Estruga A, Oliva JC, et al. Asynchronies during mechanical ventilation are associated with mortality. Intensive Care Med. 2015;41(4):633-41. https://doi.org/10.1007/s00134-015-3692-6.

29. Demoule A, Clavel M, Rolland-Debord C, Perbet S, Terzi N, Kouatchet A, Wallet F, Roze H, Vargas F, Guerin C, Dellamonica J, Jaber S, Brochard L, Similowski T. Neurally adjusted ventilatory assist as an alternative to pressure support ventilation in adults: a French multicentre randomized trial. Intensive Care Med. 2016:42(11):1723-32.

30. Colombo D, Cammarota G, Bergamaschi V, De Lucia M, Corte FD, Navalesi $P$. Physiologic response to varying levels of pressure support and neurally adjusted ventilatory assist in patients with acute respiratory failure. Intensive Care Med. 2008;34:2010-8

Ready to submit your research? Choose BMC and benefit from:

- fast, convenient online submission

- thorough peer review by experienced researchers in your field

- rapid publication on acceptance

- support for research data, including large and complex data types

- gold Open Access which fosters wider collaboration and increased citations

- maximum visibility for your research: over $100 \mathrm{M}$ website views per year

At BMC, research is always in progress.

Learn more biomedcentral.com/submissions 